Case Report

\title{
Retinitis Pigmentosa in a rare case of Bardet Beidl Syndrome
}

\author{
Sabnis M. ${ }^{1}$, Mohta A. ${ }^{2}$, Nayyar M. ${ }^{3}$, Kulkarni V. ${ }^{4}$ \\ ${ }^{1}$ Dr. Milind Sabnis, Professor and Head of the Department, ${ }^{2}$ Dr. Antariksh Mohta, MBBS, $3^{\text {rd }}$ Year Resident, ${ }^{3}$ Dr. Monica \\ Nayyar, MBBS, $3^{\text {rd }}$ Year Resident, ${ }^{4}$ Dr. Vedesh Kulkarni, MBBS, ${ }^{\text {nd }}$ Year Resident; Department of Ophthalmology at Dr. D.Y. \\ Patil Medical College Hospital \& Research Institute, Kolhapur, Maharashtra, India.
}

Corresponding Author: Dr. Milind Sabnis, Professor and Head of the Department in Department of Ophthalmology at Dr. D.Y. Patil Medical College Hospital \& Research Institute, Kolhapur, Maharashtra, India. E-mail: drmilind_11@rediffmail.com

\begin{abstract}
Retinitis pigmentosa is a rod-cone dystrophy with a prevalence of 1 in 5000 with nyctalopia and loss in peripheral field of vision. In retinitis pigmentosa there is progressive loss of rod photoreceptors majorly. Bardet Beidl Syndrome [BBS] there is presentation of atypical retinitis pigmentosa. Bardet Beidl Syndrome [BBS] is a rare ciliopathic and pleiotropic condition which is an autosomal recessive genetic disorder hampering multiple organ systems. The prevalence of Bardet Beidl Syndrome is about 1 in 150000 population globally and its incidence increases in consanguineous married people. The occurrence of the syndrome is found out to be 1:1,60,000. Only 11 cases have been reported from India out of which only one had documented end stage kidney disease requiring renal replacement therapy. It affects male and female equally. There is no specific treatment for the syndrome as it is a genetic disorder but patient can be treated symptomatically. We here present a case report of 20-year-old male patient came to our OPD with complaint of increased diminution of vision having clinical findings of retinitis pigmentosa, polydactyly, central obesity with renal involvement.
\end{abstract}

Keywords: Bardet Beidl Syndrome, Retinitis pigmentosa, Rod-cone dystrophy

\section{Introduction}

Bardet Beidl Syndrome is an autosomal recessive genetic disorder which is a rare ciliopathic and pleiotropic condition affecting multiple organ system. Consanguineous marriage of parents being a common cause. The disease is characterised by atypical retinitis pigmentosa, progressive rod cone dystrophy, myopia, central obesity, mental retardation, anisometropia, astigmatism, early cataract, postaxial polydactyly, hypogonadism in males, renal involvement [1]. Apart from the cardinal manifestations, other features of the BBS include various degrees of intellectual impairment, congenital heart block, brachycephaly, deafness and dental anomalies. The full spectrum of clinical features is found in only $40-45 \%$ of LMBBS cases [2]. Only 11 cases have been reported from India out of which only one had documented end stage renal disease (ESRD) requiring renal replacement therapy [3].
The syndrome affects males and females equally. The prevalence of the disease varies between isolated, inbred (Bedouin and Newfoundland - 1:13,500 and 1:16,000) [4] consanguineous (Arab - 1:65,000) and other populations (North America and Europe - 1:140,000 and 1:160,000) [5]. Authors here would like to report a case of 20-year-old man with ophthalmological and systemic findings Bardet Beidl syndrome. Our patient complained of diminution of vision which increased over the years and which was more during the night. Detailed history revealed that the patient was born out of a consanguineous marriage. The patient had polydactyl in upper and lower limbs, central obesity and dilated ophthalmoscopy showing characteristic retinitis pigmentosa. Patients' blood urea and creatinine levels were also raised. USG abdomen showed small kidneys and parenchymal disease.

\section{Case Report}

20 years old male patient came to the current Ophthalmology OPD with gradual, painless diminution of vision for 10 years of age which has gradually progressed over years to his current visual acuity. Diminution of vision was more during the night than in the morning. There was no past history of systemic disorders. Family history revealed patient's father and mother were blood

Manuscript received: $4^{\text {th }}$ December 2019

Reviewed: $\mathbf{1 4}^{\text {th }}$ December 2019

Author Corrected: $20^{\text {th }}$ December 2019

Accepted for Publication: 24 ${ }^{\text {th }}$ December 2019 


\section{Case Report}

relatives being first cousins. Birth history of patient revealed that he was born out of consanguineous marriage. There were no complications during antenatal or intra-natal period to mother or child. Patient was full term normal vaginal delivery, with normal birth weight, no NICU admission or cyanosis or feeding difficulties. There was delay in developmental milestones noted by the parents with onset of walking and speech at 4 and 6 years respectively.

\section{Examination}

General examination- Patient was afebrile, with normal pulse rate and blood pressure. Height and weight of the patient was $160 \mathrm{~cm}$ and $90 \mathrm{~kg}$ respectively with a resultant high body mass index of 38 which shows obesity. Polydactyly was noted in both upper and lower limbs (6 fingers in each upper limb and 6 fingers in each lower limb) with wide feet (Figure 1 and Figure 2). Patient was showed central obesity (Figure 3).

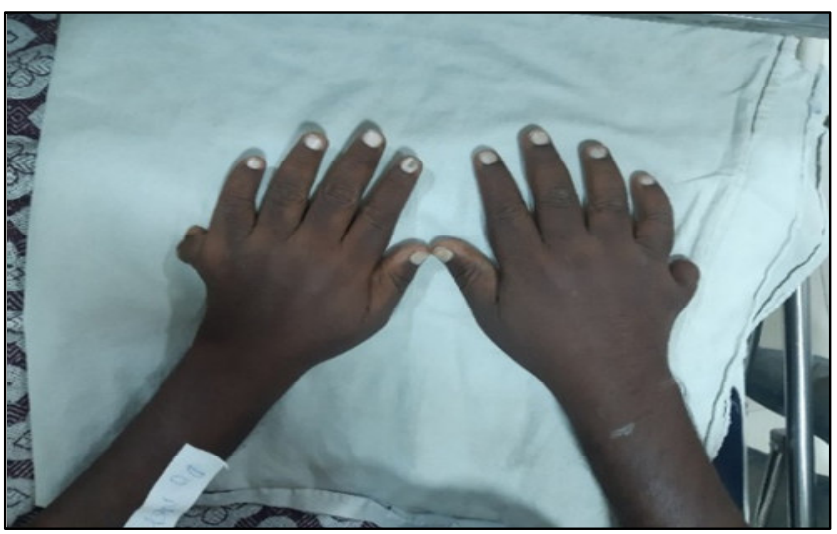

Fig-1: Polydactyl 6 fingers in each hand.

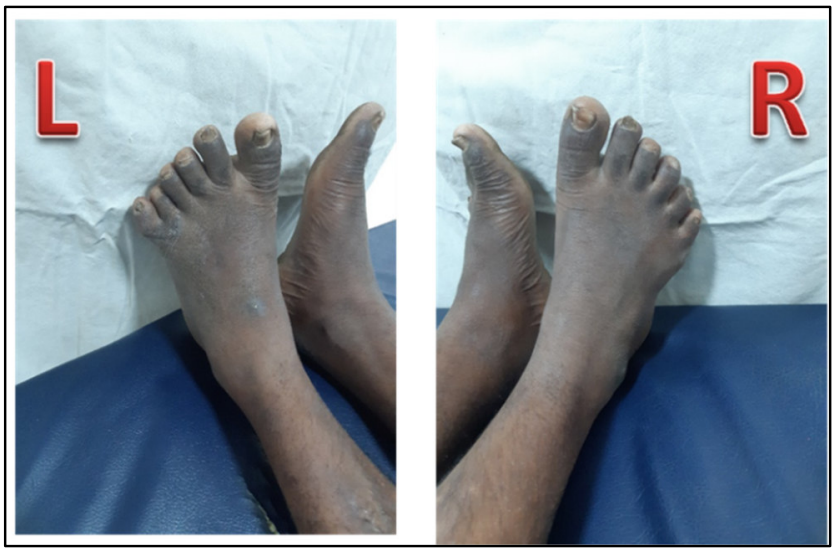

Fig-2: Polydactyl 6 fingers in each lower limb and wide feet.

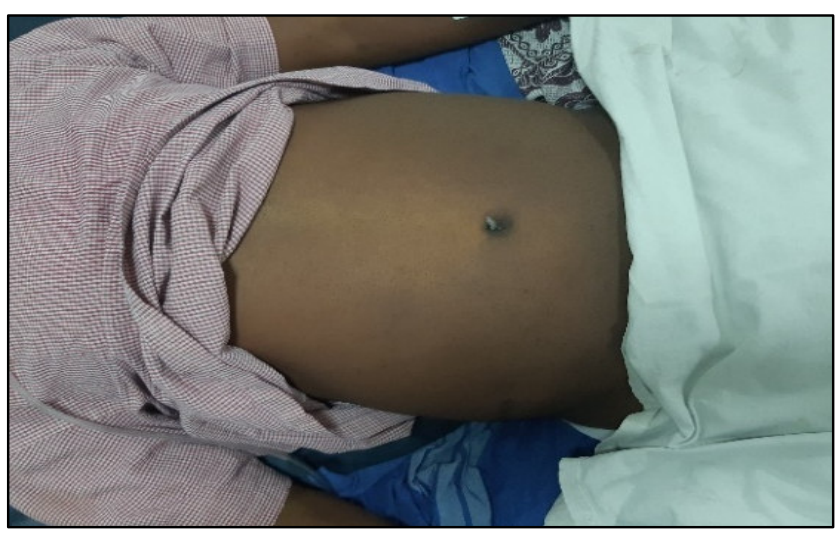

Fig-3: Central obesity. 


\section{Case Report}

Ophthalmological Examination- Both eye on diffuse light examination revealed normal anterior segment. Visual acuity of counting fingers 3 meters with BCVA 6/60 with -7.0 D Sphere correction was observed in both eyes, implying high myopia. Fundus typically showed bilateral retinitis pigmentosa with optic disc pallor (Figure 4), mid-peripheral intraretinal perivascular 'bone-spicule' pigmentary changes and RPE atrophy associated with arteriolar narrowing (Fig 5). Patient was given corrective glasses for refractive error.

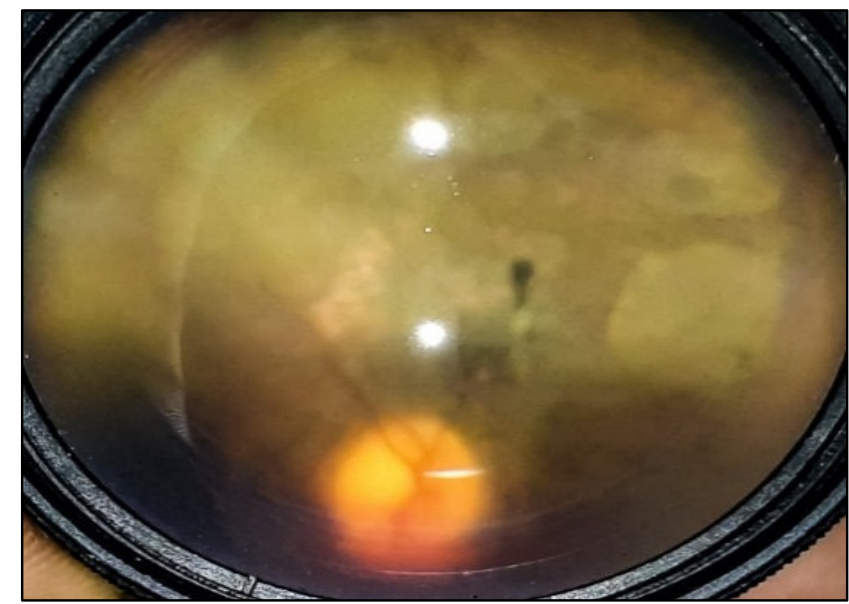

Fig-4: Pale optic disc with arteriolar narrowing (Images taken with mobile fundoscopic camera using 20D lens).

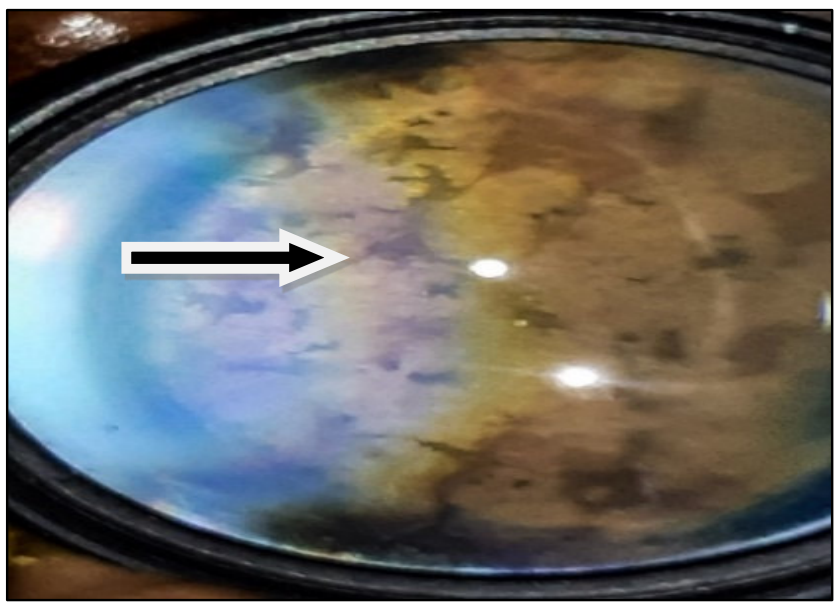

Fig-5: Mid-peripheral intraretinal perivascular 'bone-spicule' pigmentary changes (Images taken with mobile fundoscopic camera using 20D lens).

Systemic Examination- On per abdomen examination mild splenomegaly was palpated. Cardio-vascular, central nervous system, respiratory system were all within normal limits.

Investigations- Routine blood investigations were done. Blood serum urea levels were $152 \mathrm{mg} / \mathrm{dl}$ (normal value $5-15 \mathrm{mg} / \mathrm{dl}$ ), serum creatinine $19 \mathrm{mg} / \mathrm{dl}$ (normal value $0.6-1.4 \mathrm{mg} / \mathrm{dl}$ ) with normal complete blood count and random blood sugar levels. Later USG abdomen was done which showed both kidneys small in size with parenchymal disease. Mild splenomegaly was also noted in USG abdomen. Magnetic resonance imaging of the brain was performed and revealed normal study.

\section{Discussion}

The syndrome is named after Georges Bardet and Arthur Beidl [6]. The first known case was studied and reported by Laurence and Moon in 1866 at the Ophthalmic Hospital in South London. Laurence-Moon-Biedl-Bardet syndrome is no longer considered as valid terms in that patients of Laurence and Moon had paraplegia but absent polydactyly or obesity, which are the characteristics features of the Bardet-Biedl syndrome. Laurence Moon Syndrome is a separate entity. However, some recent research suggests that the two conditions may not be distinct [7]. 


\section{Case Report}

The symptoms mainly start in first 10 years of life and the first complaint of the syndrome is night blindness. Fundus changes include pale waxy disc, constricted arterioles, pigment atrophy, bone corpusular pigmentation and areas of white deposits [8]. The common cause of morbidity and mortality is renal involvement. Renal abnormalities in BBS include renal parenchymal or calyceal cysts, calyceal clubbing and blunting, scarring, renal calculi, vesico-ureteric reflex with pyelonephritis, bladder obstruction, hydronephrosis, renal agenesis, horseshoe, dysplastic or ectopic kidney. Uncommon features of the syndrome are hepatic fibrosis, behavioural traits, diabetes mellitus, facial dysmorphism, dental anomalies, developmental delay, neurological, speech and language disorder. Accessory digits are often non-functional and may be excised. Puberty is particularly a difficult time for the patients of BBS and patient need to be shown to an experienced counsellor, if necessary, testosterone supplements can also be given in male patients. Renal failure is the most common cause of death in BBS [9].

Retinitis pigmentosa (RP) presents with night blindness, tunnel vision, photophobia, photopsia, poor colour separation, latticework vision and slow adjustment from dark to light environments. Retinitis pigmentosa is a principal cause of inherited blindness [10]. with approximately $1 / 4000$ individuals experiencing the non-syndromic form of their disease within their lifetime [11]. It is estimated that 1.5 million people globally are surviving with this disease. RP can be inherited as autosomal dominant, autosomal recessive, $\mathrm{X}$-linked and mitochondrially acquired and controlled by RP gene mutations present in parental generation [12]. Mutations in the rhodopsin gene which is accountable for majority of autosomal dominant inherited RP cases, disarranges the rod-opsin protein which is responsible for translating light into decipherable electrical signals in the phototransduction cascade of central nervous system. RP can be associated with a lot of syndromes- RP with deafness(congenital or progressive) is Usher Syndrome, RP with abnormal glomerular basement membrane leading to nephrotic syndrome is Alport Syndrome, RP combines with ophthalmoplegia, dysphagia, ataxia and cardiac conduction defects is seen in Kearns Sayre syndrome, RP in association with muscular dystrophy and chronic granulomatous disease.

In this syndrome, both the parents are carriers, and both must pass the defective gene to next generation in order to manifest the disease. If both parents have the defective gene there is 1 out of 4 chance of the child having the syndrome. The IQ test determines smaller number of patients are mentally retarded and low IQ level is co-related to visual handicap.

Table 1: Dr. Beales' diagnostic criteria.

\begin{tabular}{|c|c|}
\hline $\begin{array}{l}\text { Primary features } \\
\text { include }\end{array}$ & $\begin{array}{l}\text {-Visual impairment caused by retinal abnormalities } \\
\text {-Obesity, typically apparent by age one } \\
\text {-Polydactyly (extra fingers or toes) } \\
\text {-Hypogonadism } \\
\text {-Renal anomalies (kidney malformations and/or malfunctions) } \\
\text {-Learning disabilities }\end{array}$ \\
\hline $\begin{array}{l}\text { Secondary features } \\
\text { include }\end{array}$ & $\begin{array}{l}\text {-Developmental delays } \\
\text {-Behavioural problems } \\
\text {-Neurological problems } \\
\text {-Hypertension (high blood pressure) } \\
\text {-Speech disorders } \\
\text {-Dental anomalies (small teeth, small lower jaw, short teeth) } \\
\text {-Lack of a sense of smell (anosmia) } \\
\text {-Flat, wide feet; no arches } \\
\text {-Thyroid problems } \\
\text {-Strabismus ("lazy eye" -- one eye focuses and the other wanders) } \\
\text {-Short stature relative to parents' height } \\
\text {-Toe and finger variations: short (brachydactyly); curved (clinodactyly), especially the } \\
\text { outer fingers or toes; mild webbing (syndactyly) especially between the 2nd and 3rd toes }\end{array}$ \\
\hline
\end{tabular}

Twelve genes (BBS1 to BBS12) that are responsible for the disease have been cloned. The BBS proteins are components of the centrosome and affect the ciliary transport; hence, the disease falls under the spectrum of "ciliopathies" [13]. Twelve genes are known to be associated with Bardet-Biedl syndrome: BBS1, BBS2, ARL6/BBS3, BBS4, BBS5, MKKS/BBS6, BBS7, TTC8/BBS8, B1/BBS9, BBS10, TRIM32/BBS11, and BBS12 [14]. Molecular genetic testing is available on a clinical basis for p.M390R, the common mutation in BBS1 that is present in approximately $18 \%-32 \%$ of individuals with BBS and p.C91LfsX4 (also known as C91fsX95), a common mutation in BBS10, that is present in $10 \%$ of individuals with BBS. However, despite the identification of 12 BBS genes, the molecular basis of BBS remains difficult. Through a study carried out in a roundworm, 


\section{Case Report}

C.elegans biologist concluded that BBS proteins are involved in a process called intraflagellar transport (IFT), a bi-directional transportation along the cilia along the long axis of the ciliary shaft which is necessary for ciliogenesis and maintenance of cilia [15]. A theory that IFT of the retinal cilia nourishes the photoreceptor cells is a potential explanation for the retinal dystrophy common in BBS patients after their early years of life [16,17].

According to Dr. Beales' diagnostic criteria [18], a person should be diagnosed with BBS if they have four of the primary characteristics (Table 1) or if the person had three primary characteristics and at least two secondary characteristics.

Sumit Kumar et al [19] in a case report titled 'Bardet-Biedl syndrome: A rare case report from North India' reported a rare case of Bardet Beidl Syndrome from North India with patient showing signs and symptoms of central obesity, underdeveloped genitalia and absence of hair on the pubic and axillary area, hexadactyly of hands and feet, hypogonadism with micropenis and absence of secondary sexual characters. Fundus photograph showed features of retinitis pigmentosa sine pigmento, shows indistinguishable findings to our case with polydactyl, central obesity and developmental delay.

Rathiet al [3] in a case report named 'Bardet-Biedl syndrome with end-stage kidney disease: A case report and review of literature' described the first case from India with ESRD who was treated with continuous ambulatory peritoneal dialysis. In this case report, the patient achieved normal developmental milestones, hexadactyly in her left hand which she got amputated, obesity and deranged kidney function tests, our case report also showed homogenous results with hexadactyly, central obesity, and deranged urea creatinine and small kidneys diagnosed as chronic kidney disease.

Hoodaet al [20] in a case report titled 'Renal transplant in a child with Bardet-Biedl syndrome: A rare cause of end-stage renal disease' reported a 12 year old male child having polydactyl in all the limbs, fundus changes showing retinitis pigmentosa, delayed milestones and grade III chronic kidney disease. Similar findings were recorded in my study as well with chronic kidney disease.

Additional investigation like full field electrophysiology may show decrease in the rod and cone amplitudes as early as 2 years of life. Scotopic ERGs are known to get affected before the photopic responses. Typically, these patients are characterized by unrecordable responses eventually with elevated dark-adapted thresholds. However, negative ERGs indicating greater inner than outer retinal dysfunction. On time domain-optical coherence tomography (OCT) in patients with BBS is definable lamination with thinning in and around the fovea with varying severity of paracentral thinning and normal nerve fiber layer around the optic nerve with no genotype-phenotype correlation [21].

The patient was discharged after dialysis and low protein and low-calorie diet was advised for controlling obesity and may also slow the progression of renal failure in patients with BBS. Patient is asked to follow-up 6 monthly for renal functional test.

Consanguineous marriage should be avoided and patients who have been diagnosed with this syndrome should go through thorough systemic examinations specially for renal involvement. Simons et al. described gene therapy by adeno-associated virusmediated Bbs4 delivery into the rods of Bbs4-null mice can rescue rhodopsin mis-localization in this Bbs mouse model [22] This is a first encouraging step toward preserving vision in BBS patients.

\section{Conclusion}

No effective treatment for BBS-associated retinal degeneration and progressive decrease in vision at present.

Funding: No funding sources

Conflict of interest: None declared

Ethical Approval: Not required

\section{References}

1. Bijnya BP, Anusha V, Rashmi RD, Jyotiranjan M, Susanta P. Unusual pattern of Refractive Error in Siblings of Laurence-Moon-Biedl Syndrome, J of Evidence Based Med and Healthcare, 2015; 2(33): 5053-5057. doi: 10. 18410 / jebmh/ 2015/703.
2. Prosperi L, Cordella M, Bernasconi S. Electroretinography and diagnosis of the Laurence-Moon-BardetBiedl syndrome in childhood. J Pediatr Ophthalmol. 1977; 14 (5):305-308.

3. Rathi M, Ganguli A, Singh SK, Kohli HS, Gupta KL, Sakhuja V, Jha V. Bardet-Biedl syndrome with end-stage kidney disease: A case report and review of literature. Indian J Nephrol. 2007; 17(1):10-13. doi: 10.4103/09714065. 35014.

4. Farag TI, Teebi AS. High incidence of BardetBiedl syndrome among theBedouin.ClinGenet.1989;36(6):463-464. doi:https://doi.org/10.1111/j.1399-0004.1989.Tb 03378.x 
5. Pearce WG, Gillan JG, Brosseau L. Bardet-Biedl syndrome and retinitis punctataalbescens in an isolated northern Canadian community. Can J Ophthalmol. 1984;19 (3): 115-118.

6. Gorlin RJ, Cohen MMJr, Hennekam RCM. Eds. Syndromes of the Head and Neck. 4th ed. Oxford University Press, New York, NY; 2001:pp 1186-1190.

7. Moore SJ, Green JS, Fan Y, Bhogal AK, Dicks E, Fernandez BA, et al. Clinical and genetic epidemiology of Bardet-Biedl syndrome in Newfoundland: A 22-year prospective, population-based, cohort study. Am J Med Genet. Part A. 2005;132(4):352-360. doi:10.1002/ ajmg. a. 30406.

8 Tariq Q, Ayub ARN, Mehmooda A. Laurence-Moon (Bardet) Biedl Syndrome, JK Practioner. 2003;10(3): 217-218.

9. Beales PL, Elcioglu N, Woolf AS, Parker D, Flinter FA. New criteria for improved diagnosis of Bardet-Biedl syndrome: results of a population survey. J Med Genet. 1999; 36(6):437-446. doi: http://dx.doi.org/10.1136/jmg. 36. 6.437 .

10. Parmeggiani F. Clinics, Epidemiology and Genetics of Retinitis Pigmentosa. Curr Genom. 2011;12(4):236-237. doi: $10.2174 / 138920211795860080$.

11. Hamel C. Retinitis pigmentosa. Orphan J Rare Dis. 2006; 1(1):40. doi:10.1186/1750-1172-1-40.

12. Rivolta C, Sharon D, DeAngelis MM, Dryja TP. Retinitis pigmentosa and allied diseases: numerous diseases, genes, and inheritance patterns. Human mole Genet. 2002; 11(10):1219-1227. doi:10.1093/hmg/ 11.10. 1219 .

13. Nachury MV, Loktev AV, Zhang Q, Westlake CJ, Peränen J, Merdes A, et al. A core complex of BBS proteins cooperates with the GTPase Rab8 to promote ciliary membrane biogenesis. Cell. 2007;129(6):1201-1213. doi: https://doi.org/10.1016/j.cell.2007.03.053.

\section{Case Report}

14. Hamosh A, Scott AF, Amberger J, Valle D, McKusick VA. Online Mendelian inheritance in man (OMIM). Human Mutat. 2000;15(1):57-61. doi: https://doi.org/10.1002/ (SICI) 1098-1004 (200001) 15:1<57::AID-HUMU12>3.0. $\mathrm{CO} ; 2-\mathrm{G}$.

15. Blacque OE, Reardon MJ, Li C, McCarthy J, Mahjoub MR, Ansley SJ, et al. Loss of C. elegans BBS-7 and BBS-8 protein function results in cilia defects and compromised intraflagellar transport. Gen Develop. 2004;18(13):16301642. doi:10.1101/gad.1194004.

16. Sedmak $T$, Wolfrum U. Intraflagellar transport molecules in ciliary and nonciliary cells of the retina. J Cell Biol. 2010;189(1):171-186. doi:10.1083/jcb.200911095.

17. Orozco JT, Wedaman KP, Signor D, Brown H, Rose L, Scholey JM. Movement of motor and cargo along cilia. Nature. 1999;398(6729):674. doi:10.1038/19448.

18. Bardet Biedl Syndrome Foundation. Available from: https://www.bardetbiedl.org/what-is-bbs.

19. Kumar S, Mahajan BB, Mittal J. Bardet-Biedl syndrome: A rare case report from North India. Indian $\mathrm{J}$ Dermatol Venereol Leprol. 2012;78(2):228. doi: 10.4103/ 0378-6323.93656.

20. Hooda AK, Karan SC, Bishnoi JS, Nandwani A, Sinha T. Renal transplant in a child with Bardet-Biedl syndrome: A rare cause of end-stage renal disease. Indian J Nephrol. 2009;19(3):112-114. doi: 10.4103/0971-4065.57108.

21. Azari AA, Aleman TS, Cideciyan AV, Schwartz SB, Windsor EA, Sumaroka A, et al. Retinal disease expression in Bardet-Biedl syndrome-1 (BBS1) is a spectrum from maculopathy to retina-wide degeneration. Invest Ophthalmol Vis Sci. 2006; 47(11): 5004-5010. doi: https:// doi. org/ 10.1167/iovs.06-0517.

22. Simons DL, Boye SL, Hauswirth WW, Wu SM. Gene therapy prevents photoreceptor death and preserves retinal function in a Bardet-Biedl syndrome mouse model. Proc Natl Acad Sci USA. 2011; 108(15):6276-6281. doi: 10. 1073/pnas.1019222108. Epub 2011 Mar 28.

\section{How to cite this article?}

Sabnis M, Mohta A, Nayyar M, Kulkarni V. Retinitis Pigmentosa in a rare case of Bardet Beidl Syndrome. Trop J Ophthalmol Otolaryngol.2019;4(8):496-501.doi:10.17511/jooo.2019.i08.07 